\title{
Nitrite reduction over Pd supported CNFs: Metal particle size effect on selectivity
}

\author{
J. K. Chinthaginjala ${ }^{\text {a }}$, A. Villa ${ }^{\text {b }}$, D.S. Su ${ }^{\text {b }}$, B.L. Mojet ${ }^{a}$, L. Lefferts ${ }^{{ }^{*}}$ \\ ${ }^{a}$ Catalytic Processes and Materials, IMPACT and MESA+, University of Twente, \\ PO Box 217, 7500 AE, Enschede, the Netherlands \\ ${ }^{b}$ Department of Inorganic Chemistry Fritz-Haber-Institut der Max-Planck-Gesellschaft Faradayweg 4-6 \\ D-14195 Berlin, Germany \\ "Corresponding author: e-mail l.lefferts@utwente.nl,
}

Received 4 July 2011; revised 5 November 2011; Accepted 7 November 2011. Available online 3 December 2011

\begin{abstract}
Pd catalysts supported on carbon-nano-fibres (CNFs) were synthesized via Pd colloids stabilized with polyvinyl-alcohol (PVA). Pd catalysts with narrow particle sizes distributions and mean Pd sizes between 2.6 and 30nm were immobilized on CNFs. Characterization with COchemisorption and transmission electron microscopy (TEM) revealed that a significant part of the Pd surface is blocked by the polymer layer on the Pd particles. The prepared catalysts were tested for nitrite reduction in water, resulting in formation of nitrogen and ammonia. Turn over frequencies were found to be independent of Pd particle size while selectivity to ammonia clearly decreased with increasing Pd particle size.
\end{abstract}

Keywords: Palladium; PVA, Nitrite-hydrogenation, Particle-size-effect

\section{Introduction}

Ground water pollution by nitrates and nitrites is a widespread problem all over the world and a potential risk for public health. Contaminants can be removed with conventional physicochemical methods (ion exchange, reverse osmosis and electro-dialysis) and biological methods.[1] However, the existing technology removes contaminants by concentrating, resulting in a more concentrated secondary waste stream. Therefore, conversion of nitrate is a better approach. Nitrate and nitrite removal by liquid phase hydrogenation using noble metal catalysts is one of the most promising techniques. In this process, nitrates and nitrites are converted to nitrogen in a three-phase reactor system.[2]

The key issue in this process is finding a suitable catalyst with sufficiently high selectivity to $\mathrm{N}_{2}$. As ammonia is also undesirable in drinking water, the formation of ammonia needs to be suppressed almost completely. To reduce nitrates, it is necessary to activate the precious metal based catalysts by addition of a second metal such as $\mathrm{Cu}$, $\mathrm{Sn}$ and In which in the first step converts nitrate into nitrite.[3-5] Nitrate is an extremely stable ion and therefore abstraction of the first $\mathrm{O}$-atom of nitrate to form nitrite needs a less noble metal than Pd or Pt. Subsequently, nitrite is converted into nitrogen and/or ammonia. As a result, palladium-copper catalysts are most active and selective for nitrate reduction to $\mathrm{N}_{2}$, whereas palladium catalysts are preferred for nitrite reduction.

The catalytic conversion of nitrate to nitrite by transition metals is reported to be structure insensitive,[6] whereas Yoshinaga et al.[7] found that nitrite reduction is structure sensitive with respect to the two main products formed. It is proposed that on Pd low coordination sites like edge and corner sites are particularly active for hydrogenation, resulting in deep hydrogenation to ammonia. Terrace sites, on the other hand, are suggested to be less active, forming mainly nitrogen. Miyazaki et al.[8] reported similar results for Pt supported on alumina based on an elegant 
study, varying the dominant exposed facets via the shape and morphology of the Pt particles.

It is well known that nitrite reduction is an extremely fast reaction, so that concentration gradients in the internal of catalyst particles or catalyst layers can easily occur, influencing reaction rates and selectivity. Our previous work [9] demonstrated that catalysts supported on thin macroporous layers of entangled Carbon-Nano-Fibers (CNF) provide efficient mass transfer, thus resulting in intrinsic rates and selectivity. Further, for Pd-CNF catalysts with large Pd particles (Pd dispersion $5-10 \%)$ the nitrite turn-overfrequency (TOF) was found to be constant within the experimental error, which can be explained by the large Pd particle size. In this paper, we investigate the effect of Pd particle size in a much broader range on the activity and selectivity of nitrite reduction to nitrogen and ammonia. CNF layers on Ni foam (hairy foam Fehler! Textmarke nicht definiert.) were used as catalyst support for Pd particles, in order to ensure that intrinsic catalyst performance data on nitrite hydrogenation are obtained. Pd nano-particles were prepared using polyvinylalcohol (PVA) as stabilizer and $\mathrm{NaBH}_{4}$ as reducing agent. This preparation method allows tuning of particle sizes with narrow particle-sizedistribution by varying the concentration of protective agent and Pd salt.[10,11] In this way catalysts with Pd particle sizes ranging from 2 to $30 \mathrm{~nm}$ were obtained. Results are presented that show the effect of Pd particle size and the presence of PVA on nitrite conversion and selectivity.

\section{Experimental}

\subsection{Materials}

$\mathrm{Na}_{2} \mathrm{PdCl}_{4}$ (99.99\%, Aldrich), $\mathrm{NaBH}_{4}$ of purity (> 96\%, Fluka), polyvinylalcohol (PVA) of molecular weight 13000-23000 (87-89\% hydrolysed, Aldrich) were used to prepare colloids of Pd particles on carbon nanofibers.

\subsection{CNF-Ni foam preparation}

Nitrogen (99.999\%, INDUGAS) and ethylene (99.95\%, PRAXAIR) were used for CNFs formation without further purification. Hairy foams were prepared by growing CNFs on $\mathrm{Ni}$ foam at $440^{\circ} \mathrm{C}$ by using $25 \%$ ethylene in nitrogen as described in detail previously [9] and the CNFs were not further pre-treated.

\subsection{Catalyst preparation}

The catalysts were prepared following the procedure reported by Villa et al.[12] aiming to achieve approximately $1 \mathrm{wt} \%$ of Pd on carbon in hairy foams. As an example the preparation of $3 \mathrm{~nm}$ Pd particles is described in detail. Solid $\mathrm{Na}_{2} \mathrm{PdCl}_{4}(0.043 \mathrm{mmol})$ and $880 \mu \mathrm{l}$ PVA solu- tion (2 wt\% in water) (Pd/PVA 1:1 wt/wt) were added to $130 \mathrm{ml}$ of $\mathrm{H}_{2} \mathrm{O}$ at room temperature. After $3 \mathrm{~min}, 860 \mu \mathrm{l}$ of $0.1 \mathrm{M} \mathrm{NaBH}_{4}$ solution was added to the yellow-brown solution under vigorous magnetic stirring resulting in $\mathrm{pH}$ around 9. The brown Pd colloids were immediately formed. Within ten minutes after their formation, the colloids were immobilized by adding the support. After 2 hours, excess liquid was removed by filtration whereafter the catalyst containing Pd colloid was washed with distilled water and finally the samples were dried at $373 \mathrm{~K}$ for $4 \mathrm{~h}$. The samples were prepared by varying amounts of $\mathrm{Na}_{2} \mathrm{PdCl}_{4}$ and PVA solution. The ratio of quantities of PVA solution and $\mathrm{Na}_{2} \mathrm{PdCl}_{4}$ solution was altered in order to vary the colloid particle size as shown in Table 1.

\subsection{Catalytic hydrogenation of nitrite}

Catalytic hydrogenation of nitrite was performed in a fixed bed reactor placed in an oven at $298 \mathrm{~K}$. Nitrite concentration in the aqueous reactant solution was always maintained at $\sim 20 \mathrm{mg} / 1(435 \mu \mathrm{mol} / \mathrm{l})$ and the $\mathrm{pH}$ of the solution was maintained at 7 by adding sodium hydroxide. The solution was pre-saturated with hydrogen at a hydrogen partial pressure of 0.4 bar (balance argon), resulting in a concentration of dissolved $\mathrm{H}_{2}$ equal to $312 \mu \mathrm{mol} / \mathrm{l}$, based on Henry's coefficient. The reactor was made of PEEK (polyether-ether-ketone) and the diameter was optimized in order to exactly fit with the size of the cylinder shaped pieces of hairy foam catalysts (diameter $4.5 \mathrm{~mm}$ ). Liquid containing nitrite and dissolved hydrogen was pumped through the fixed bed reactor at a flowrate of $8 \mathrm{ml} / \mathrm{min}$ with an HPLC pump (DIONEX, Ultimate 3000). Nitrite and ammonium concentrations in the reactants and products were measured with ion-chromatography (DIONEX, ICS 1000). The reaction was performed under differential conditions by varying the catalyst amount keeping nitrite conversions below 6\%; as a result, concentration gradients along the axis of the reactor were not significant. The rate of nitrite reduction was expressed in terms of activity per gram of Pd per second.

It is known that nitrite ions are converted to ammonium and nitrogen exclusively under the conditions used in this study $[9,13]$ the yield of nitrogen was therefore calculated from the difference between the nitrite conversion and the ammonium yield.

\subsection{Characterization}

Inductively coupled plasma (Jobin Yvon JV24) was used to determine the palladium loadings on CNF-Ni foam.

CO-chemisorption (Micromeritics, ChemiSorb 2750: Pulse Chemisorption system) at room temperature was used to determine the dispersion of palladium assuming a ratio of $1: 1$ for the number of adsorbed $\mathrm{CO}$ molecules and number of Pd surface atoms. Before introducing $\mathrm{CO}$, the 
Table 1. Characterization data obtained for Pd-CNF catalysts

\begin{tabular}{|c|c|c|c|c|c|}
\hline \multirow{2}{*}{$\begin{array}{l}\text { Pd colloids on CNF-Ni } \\
\text { foam }\end{array}$} & \multirow{2}{*}{$\begin{array}{c}\text { Pd / PVA } \\
\text { ratio } \\
(w t / w t) a\end{array}$} & \multirow{2}{*}{$\begin{array}{c}\text { Pd wt \% } \\
\text { (based on weight of } \\
\text { carbon) }\end{array}$} & \multirow{2}{*}{$\begin{array}{c}\text { CO- } \\
\text { chemisorption }\end{array}$} & \multicolumn{2}{|c|}{ Transmission electron microscopy (TEM) } \\
\hline & & & & $\begin{array}{c}\text { Mean Pd particle size, } \\
\text { nm }\end{array}$ & $\begin{array}{c}\text { Pd dispersion, } \\
\%\end{array}$ \\
\hline Sample 1 & $1 / 1$ & 0.95 & $1.4 \pm 0.5 b$ & 2.6 & 56 \\
\hline Sample 2 & $1 / 0.5$ & 0.94 & n.d. $*$ & 4.4 & 33 \\
\hline Sample 3 & $1 / 0.25$ & 0.97 & n.d. $*$ & 7.1 & 21 \\
\hline Sample 4 & $1 / 0.125$ & 0.88 & $0.7 \pm 0.2 b$ & 30.5 & 5 \\
\hline
\end{tabular}

a. In all preparations [Pd $\left.{ }^{\mathrm{II}}\right]$ was adjusted to $3.3 * 10^{-4} \mathrm{M}$

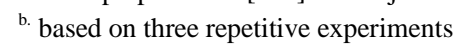

* not determined
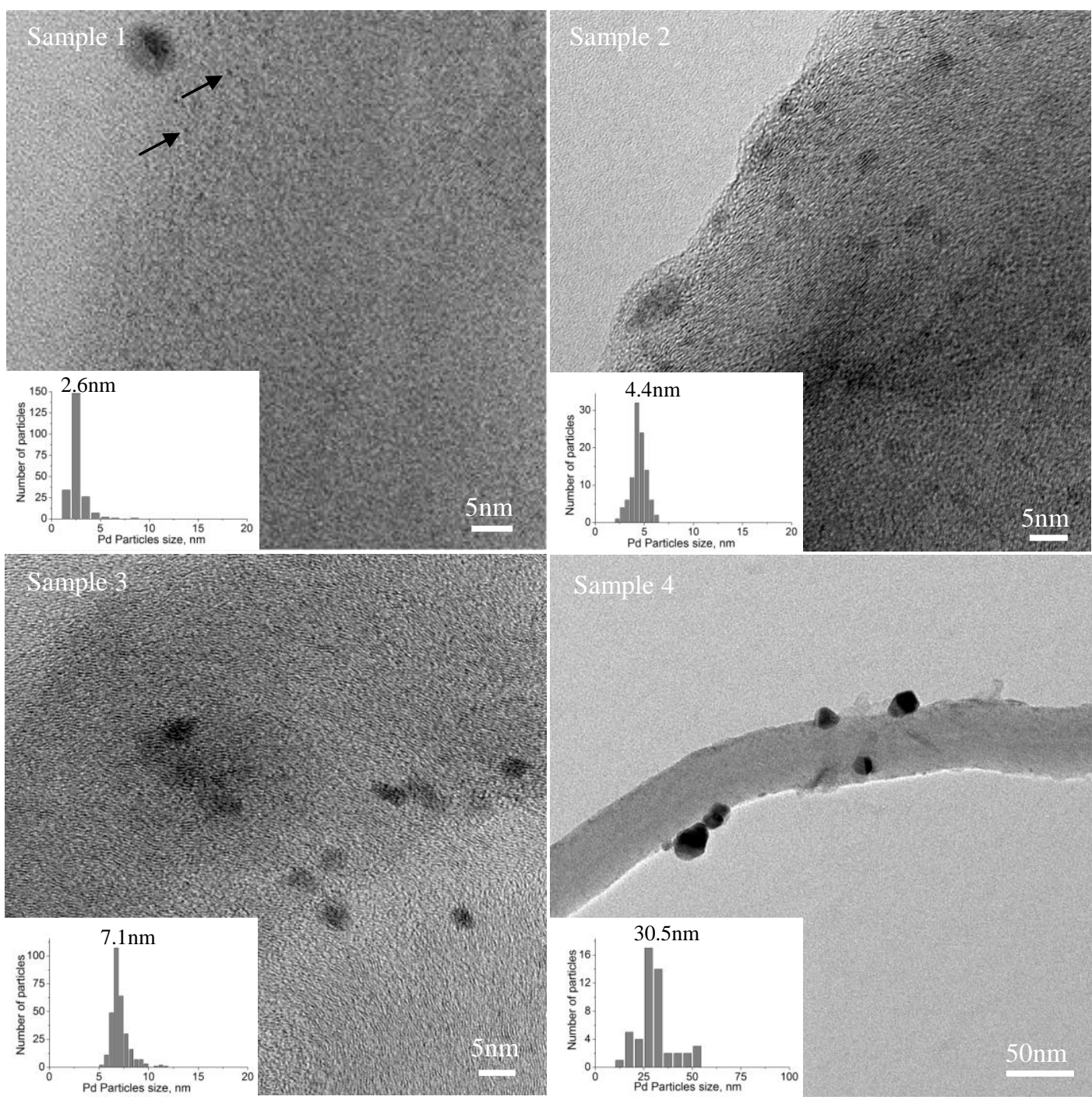

Figure 1. TEM images and respective histograms of palladium particle size distribution deposited on Hairy foam samples 1-4. 


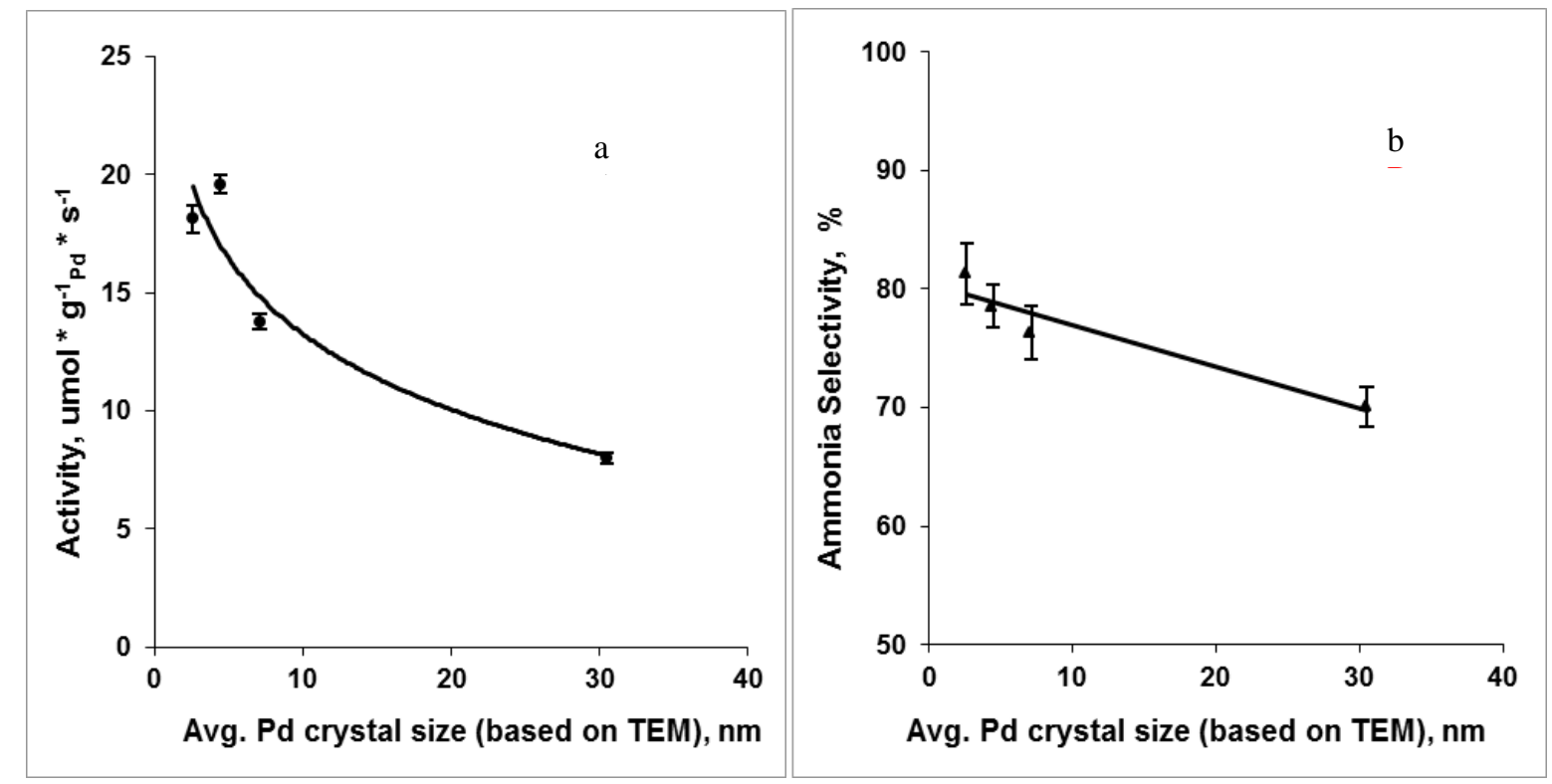

Figure 2: Influence of the Pd particle size on the activity per gram of palladium (a) and ammonia selectivity (b) during nitrite reduction for Pd supported CNF-Ni foam.

catalyst was reduced in flowing hydrogen at room temperature. Since the adsorbed volume of $\mathrm{CO}$ was extremely low, the $\mathrm{CO}$ chemisorptions experiments were carried out with $1 \% \mathrm{CO}$ in $\mathrm{He}$ to increase sensitivity.

The palladium particle size distribution was determined with Transmission Electron Microscopy (TEM Philips CM300ST-FEG). Mean palladium dispersions were calculated from the Pd particle size distribution assuming hemi-spherical metal particles and using a Pd molar volume of $8.9 \mathrm{~cm}^{3} \cdot \mathrm{mol}^{-1}$.

\section{Results}

\subsection{Characterization}

Figure 1 presents the TEM pictures and corresponding palladium particle size distributions of samples 1 to 4 . Between fifty and two hundred Pd particles were measured and the resulting mean particle sizes and calculated dispersions are reported in Table 1.

Table 1 also presents Pd dispersions based on COchemisorption for two catalysts. Unfortunately, the other two samples could not be measured accurately. Sample 1 was also measured after catalytic testing and it was observed that the capacity for $\mathrm{CO}$ chemisorption remained constant within the accuracy of the $\mathrm{CO}$ adsorption experiment.

\subsection{Catalytic hydrogenation of nitrite}

The performance of the four catalysts in nitrite hydrogenation is shown in Figures $2 \mathrm{a}$ and $2 \mathrm{~b}$, presenting the activity and ammonia selectivity at similar conversion as a function of Pd particle size. Clearly, both activity per gram $\mathrm{Pd}$ and selectivity to ammonia decrease with increasing Pd particle size.

\section{Discussion}

From Figure 1 it is clear that CNF-supported Pd particles with varying size and narrow size distributions can be prepared using PVA as a stabilizing agent. This is qualitatively in agreement with data reported in literature on the preparation of gold particles.[11] A similar method, though at lower $\mathrm{pH}$, was used to deposit Pd colloids[12] on oxidized carbon nanotubes, resulting in particles of 3 to $4 \mathrm{~nm}$, comparable to $2.6 \mathrm{~nm}$ on hairy foam $\mathrm{CNF}$ in this study.

The Pd dispersion estimated with CO-chemisorption largely differs from the values obtained from TEM (Table 1). For the smallest particles, the $\mathrm{CO}$-chemisorption value is approximately 40 times lower than the dispersion based on the TEM data, while for the largest particles it differs by a factor of approximately 7 . The most obvious explanation for the difference in dispersion as found with chemisorption and TEM is the presence of PVA on the surface of the Pd particles, blocking part of the surface Pd atoms. Similar differences were observed on PDDA covered Pd particles.[14] 


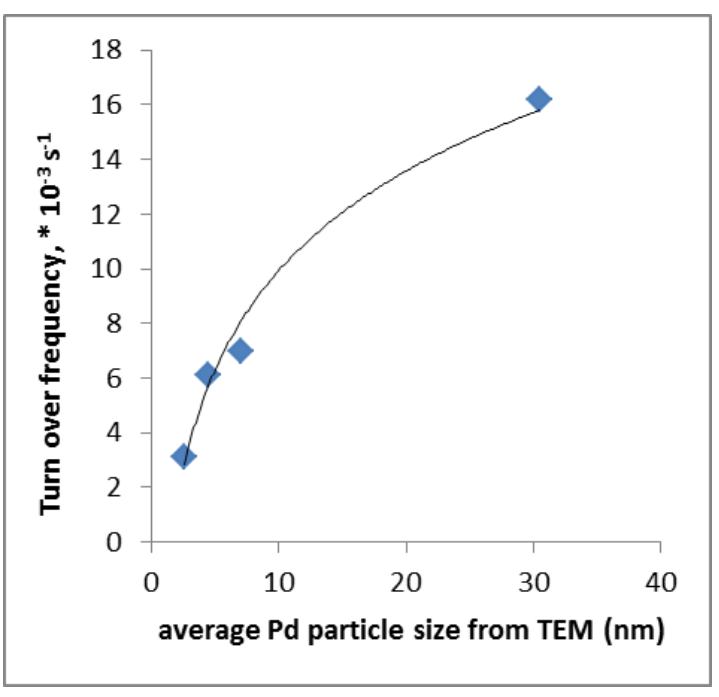

Figure 3. Effect of palladium particle size on turn-over-frequency for nitrite reduction over Pd supported CNF-Ni foam estimated based on TEM analysis.

Nitrite hydrogenation activity per gram of palladium decreased with increasing Pd particle size above 5nm (Figure 2a) which is explained by the decreasing number of surface sites with increasing particle size. Figure 3 presents the apparent TOFs as a function of particle size as determined from TEM. TOFs were calculated from the data in Figure 2a using the dispersions as calculated from TEM (Table 1)

Clearly, the apparent TOFs reported in Figure 3 increase with increasing particle size and are 5 times larger for $30 \mathrm{~nm}$ compared to $2.6 \mathrm{~nm}$ palladium particles. The calculated TOF is based on two assumptions, first the particles are assumed to be hemispherical, independent of size, and second all surface sites are taken into account when calculating the TOF thus ignoring any effect by PVA on the surface of the metal particles. The difference in dispersion found with chemisorption and TEM already suggested that PVA might affect the available palladium surface sites. Figure 4 shows the amount of PVA per palladium surface atom as a function of metal particle size. The values in Figure 4 were calculated from the amount of PVA per amount of palladium divided by the dispersion from TEM, both taken from Table 1 .

The amount of PVA per palladium surface atom steadily decreases with palladium particle size as obtained from TEM. This can be explained by the fact that larger particles need less surface stabilization because of their size. In the formation of colloids it has been suggested that PVA coordinating to large palladium particles has a more regular structure than on smaller particles resulting in a lower amount of PVA per palladium surface site.[15] In addition, it was shown recently that PVA interacts with its $\mathrm{OH}$-groups coordinated to the $\mathrm{Pd}^{0}$ atoms more strongly for smaller Pd particles than for larger particles.[16] The stronger effect of PVA on smaller particles is also reflected in the differences of chemisorption versus TEM data shown

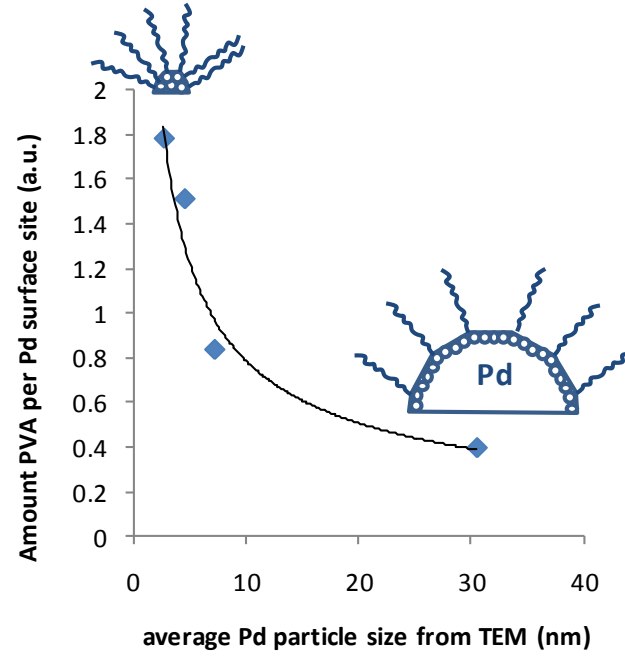

Figure 4. Amount of PVA per palladium surface site calculated from Table 1 together with a pictorial view for the smallest and the largest palladium particles.

in Table 1. Intriguingly, the ratio of PVA per palladium surface atom is approximately 4.5 times less on $30 \mathrm{~nm}$ than on $2.6 \mathrm{~nm}$ particles (Figure 4) which corresponds surprisingly well with the observed 5 times difference in the apparent TOF (Figure 3). This indicates that the actual TOF's for the palladium particles in fact might be constant, independent of particle size. Calculation of TOF based on the $\mathrm{CO}$ chemisorption data, despite the limited accuracy, results in very similar numbers $\left(0.15 \pm 0.05 \mathrm{~s}^{-1}\right)$ for $2.6 \mathrm{~nm}$ and $30 \mathrm{~nm}$ particles which also suggests that the actual TOF remains constant with changing particle size.

In our previous work $[9,13]$ TOFs of $0.021 \mathrm{~s}^{-1}$ (based on $\mathrm{CO}$ chemisorption) were reported for hairy foam supported Pd particles of varying dispersion from 5 to $10 \%$. These catalysts were prepared without PVA, thus having much a much broader size distribution, and no PVA coordinating to the palladium surface. That apparent TOF of $0.021 \mathrm{~s}^{-1}$ is in the same order of magnitude as the value of $0.016 \mathrm{~s}^{-1}$ reported in Figure 3 for $30 \mathrm{~nm}$ particles. The approximate seven times higher TOF found in the current study based on $\mathrm{CO}$ chemisorption $\left(0.15 \mathrm{sec}^{-1}\right)$ may originate from three causes. Either the presence of PVA on the Pd surface increases the activity of neighboring free Pd sites or PVA covers predominantly less active Pd sites, leaving higher active sites accessible. The third possible explanation is that measuring available $\mathrm{Pd}$ sites for $\mathrm{CO}$ chemisorption in the gas phase is not representative for the applied reaction conditions during nitrite hydrogenation. The configuration of PVA molecules on the Pd surface is likely to be influenced by the presence of water, implying that the extent of blocking Pd sites is probably different in gas-phase and water. $\mathrm{CO}$ chemisorption measurements in water would be required to settle this issue.

In short, we have obtained support for the hypothesis that the TOF of Pd catalysts for nitrite hydrogenation is independent of palladium particle size from 2.6 to $30 \mathrm{~nm}$. 
This seems to be in disagreement with the results of Miyazaki et al.[8] on nitrite hydrogenation with cubic shaped $\mathrm{Pt}$ particles on alumina, and traditional Pt on alumina catalysts. TOFs were reported to be constant in the window of Pt-particle size between 10 and $40 \mathrm{~nm}$, whereas a much lower value was observed for a catalyst with $2 \mathrm{~nm}$ cubic Ptparticles. In the current study TOFs were constant for Pd particles from $2.6 \mathrm{~nm}$ to $30 \mathrm{~nm}$ and the difference with the results of Miyazaki could be due to (i) the different metals studied (Pt versus $\mathrm{Pd}$ ), (ii) mass transfer limitations in their study which could become significant with very small particles, (iii) presence of PVA on our particles or (iv) that specifically shaped particles (cubic) do experimentally reveal structure sensitivity while poly-crystalline particles do not.

It is evident that selectivity to ammonia, and thus also selectivity to $\mathrm{N}_{2}$, depends on palladium particle size (figure $2 b$ ). This relation must be due to intrinsic differences in catalytic properties of the metal particles, because mass transfer limitations have been excluded [9] and experiments were performed at differential conditions. In our previous work, $[9,13]$ ammonia selectivities above $85 \%$ were reported for hairy-foam supported Pd catalysts with different metal loading and Pd dispersion lower than $10 \%$. The highest ammonia selectivity in the current study (82\%) is close to that, but for much smaller particles $(2.6 \mathrm{~nm})$. Ammonia selectivity further steadily decreases with increasing Pd particle size to approximately $70 \%$ for $30 \mathrm{~nm}$ particles (Figure 2b). Yoshinaga et al.[7] proposed a model to explain the different selectivity observed over $\mathrm{Cu} / \mathrm{Pd}$ carbon catalysts for nitrate hydrogenation at high conversion levels. Their results were rationalized by assuming that low coordination sites have higher activity for hydrogenation, boosting activity and selectivity to ammonia, whereas terrace sites would be responsible for mild hydrogenation

\section{References}

[1] Kapoor, A.; Viraraghavan, T. J. Environ. Eng. 1997, 123, 371-380.

[2] Pintar, A.; Bercic, G.; Levec, J. AIChE 1998, 44, 2280-2292.

[3] Hörold, S.; Tacke, T.; Vorlop, K. D. Environ. Tech. 1993, 14, 931-939.

[4] Hörold, S.; Vorlop, K.D.; Tacke, T.; Sell, M. Catal. Today, 1993, 17, 21-30.

[5] Prüsse, U.; Hähnlein, M.; Daum, J.; Vorlop, K.D. Catal. Today 2000, 55, 79-90.

[6] Pintar, A.; Batista, J.; Levec, J.; Kajiuchi, T. Appl. Catal. B 1996, 11, 81-98.

[7] Yoshinaga, Y.; Akita, T.; Mikami, I.; Okuhara, T. J. Catal. 2002, 207, 37-45.

[8] Miyazaki, A.; Asakawa, T.; Nakano, Y.; Balint, I. Chem. Comm. 2005, 3730-3732.

[9] Chinthaginjala, J.K.; Bitter, J.H.; Lefferts, L. Appl. Catal. A 2010, 383, 24-32.

[10] Dimitratos, N.; Villa, A.; Prati. L. Catal. Lett. 2009, 133, 334-340.

[11] Villa, A.; Wang, D.; Su, D.S.; Veith, G.M.; Prati, L. Phys. Chem. Chem. Phys. 2010, 12, 2183-2189. to $\mathrm{N}_{2}$. Our results agree with this picture: larger particles have more terrace sites, favoring the formation of $\mathrm{N}_{2}$, thus lowering the ammonia selectivity. It should be noted though that given the complex role that PVA seems to have in determining activity, it cannot be ruled out that the PVA molecules also affect the selectivity of the catalysts, this is subject of future studies.

\section{Conclusion}

$\mathrm{Pd} / \mathrm{CNF}$ catalysts with discrete Pd particle sizes varying from $2.6 \mathrm{~nm}$ to $30 \mathrm{~nm}$ showed constant intrinsic TOFs during nitrite reduction in water, resulting in formation of nitrogen and ammonia, despite the complicating presence of PVA. While TOFs were found to be independent of metal particle size, selectivity to ammonia clearly decreased with increasing Pd particle size. The exact effect of the presence of PVA on the selectivity was not yet established.

\section{Acknowledgements}

This work was performed with the financial support from STW, Stichting Technische Wetenschappen, Dutch funding organization (STW project \# 6601). The authors greatly acknowledge RECEMAT for supplying $\mathrm{Ni}$ foam. We are grateful to K. Altena-Schildkamp for COchemisorption measurements and Dr. E.G. Keim for TEM analyses. We acknowledge Ing. B. Geerdink for technical support.
[12] Villa, A.; Wang, D.; Dimitratos, N.; Su, D.S.; Trevisan, V.; Prati, L. Catal. Today 2010, 150, 8-15.

[13] Chinthaginjala, J.K.; Lefferts, L. Appl. Catal. B 2010, 101, 144-149.

[14] Sarkany, A.; Beck, A.; Horvath, A.; Revay, Z.; Guczi, L. Appl. Catal. A 2003, 253, 283-292.

[15] Hoogsteen, W.; Fokkink, L.G.J. J. Coll. Int. Sci. 1995, 175, 12-26.

[16] Roy, P.S.; Bagchi, J.; Bhattacharya, S.K. Coll. Surf. A: Physicochem. Eng. Aspects 2010, 359, 45-52. 